\title{
VISUAL IDENTITIES OF POLISH TOWNS AND CITIES. WHAT THEY COMMUNICATE AND REPRESENT IN PRACTICED LOGOS
}

\author{
Anna Adamus-Matuszyńska ${ }^{1}$, Piotr Dzik ${ }^{2}$ \\ ${ }^{I}$ Department of Public Management and Social Sciences, University of Economics in Katowice, \\ ul. 1 Maja 50, Katowice, Poland \\ ${ }^{2}$ Faculty of Design, Academy of Fine Arts in Katowice, ul. Raciborska 37, Katowice, Poland, \\ E-mails: ' anna.adamus-matuszynska@ue.katowice.pl (corresponding author); ${ }^{2}$ piotr.dzik@asp.katowice.pl
}

Received 28 February 2020; accepted 05 May 2020

\begin{abstract}
The purpose of the research is the empirical verification of the authors' hypothesis that the logo or City Visual Identity System (CVIS) is the indicator of marketing and branding orientation of a particular self-government. The first objective of the article is to present an empirical base for city logo examination taking into account the visual signs of Polish towns used in promotional activities. The second objective is to analyse the content of logo. To reach the objectives the authors examined 335 cities' logo in Poland using quantitative and qualitative content analysis. During the research 211 (63\%) of the cities surveyed used the logo in promotional practice. The study confirms the hypothesis that the city's $\operatorname{logo}$ can be used as a preliminary indicator of the local government's marketing orientation. The content analysis indicates that marketing activities are based primarily on resources (Ger. Substanz) of cities, not on products offered.
\end{abstract}

Keywords: local government, logo, city brand identity, city branding, territorial marketing.

JEL Classification: H70, H83, M31, M38.

\section{Introduction}

Nowadays, image, picture and screen are concepts that characterize global culture. The 21 st century man lives in an environment in which graphic message, drawing, photo, film, 3D animation disclose content relevant to the sender and recipient. The image dominated communication and displaces traditional verbal communication (P. Fuery \& K. Fuery, 2003; Bekkers \& Moody, 2015). Every person creates images in his/her own mind, which are the result of a two-way process between the social environment and the observer (Lynch, 1960, pp. 6-8). The visual message today applies to every person, organization, product and place. Cities, regions, countries use tools to communicate with the environment in a variety of ways, also taking advantage of images that carry information and messages. That is why, the main intention of the paper is to incorporate into city branding and place marketing researches graphic analysis of the visual signs, particularly logos, used in the branding and marketing practice of local governments. The authors assume that the logo is essential element of place identification, as it is widely used in geographical and virtual space and thus visible to stakeholders. Therefore, the main purpose of this study is the initial verification of the hypothesis put forward by the authors in the article Measurement of local government units marketing orientation (Adamus-Matuszyńska \& Dzik, 2017b). This hypothesis assumes that the use of a logo or city visual identification system (CVIS) indicates the marketing orientation of the local government.

The second purpose of this paper is a comprehensive description and analysis of visual identity of towns and cities in Poland in terms of their logos - signatures $^{1}$ - that disclose specifics of the place, being at the same time its major symbol. The authors have undertaken an attempt to check the regularity of the application of existing logos to visualize the essentials of Polish self-government territorial units. Making a numerical compilation

\footnotetext{
${ }^{1}$ For the purposes of this article the term 'signature' is used following the definition of Alina Wheeler presented in the book Designing Brand Identity (Wheeler, 2018, p. 54), where she stresses that a signature consists of three key components: a logotype, brandmark and tagline. Logotype (wordmark) is an organisational name written in standardized form; brandmark (graphic symbols, trademarks) is a sign vested with a certain kind of emotional appeal and power (Gibbs, 2014, p. 7); tagline is: a slogan, endline, strapline, pay-off (Barry, 2016, p. 99)
} 
and analysis of visual signs the authors provide to other researchers - sociologists, experts analysing promotion of the cities and graphic designers research data, which may encourage them for further exploration of the logo issue. This analysis can also be used for the initial verification of the hypothesis that marketing activities of cities in Poland are based mainly on resources, but not on products (cf. Kozak, 2009).

The scientific literature on place marketing mostly focuses on models and analyses of various case studies (Lucarelli \& Berg, 2011; Glińska, 2016; Vuignier, 2017). Meanwhile, the theory of marketing and territorial branding insofar notes the importance of the CVIS in the process of creating and managing a territorial brand. However, the work of graphic design theory as being able to influence territorial brand models is not recorded. (Kotler et al., 1993, pp. 153-155; Dinnie, 2014, pp. 41-51; Soenen \& Moigenon, 2003, p. 137; Anttiroiko, 2014, pp. 53-54). In one of the most frequently citied article How corporate visual identity supports reputation its authors clearly state that designers develop distinctive, authentic visual identities (van den Bosch et al., 2004, p. 112). This is why the authors ask the following research questions:

(1) What symbols are used in the visual presentation of cities and towns in Poland?

(2) What content do logos contain?

(3) Is the use of categories developed on the ground of graphic design theory stimulating branding research and do they cognitively influence on models and theoretical considerations crucial for place marketing?

Nowadays, many cities and regions search for a method to reveal their specific characteristics, as well as to emphasize their uniqueness. Therefore, marketing practices are the typical operations of cities and regions management, with particular emphasis on promotional activities. Thus, in such projects as marketing strategies or plans, one can find many proposals for the process of building a visual identity. Authors assume, according to David Gibbs, that a 'brand', including cities and towns brands, is the kind of psychological disposition in the minds of the public and its visual representation by a logo (brandmark) (Gibbs, 2014, p. 9).

The starting point of the research is the Per Mollerup's taxonomy model concerning the visual identity of the brand (products, companies, events, and places), which is based on numerous studies of this author (Mollerup, 2013). The referred model is practiced and has also found recognition among designers. In the literature devoted to the place marketing, albeit emphasizing the importance of the visual identity, there is almost no reference to the work of graphic designers. Graphic designers who have elaborated a methodological and theoretical basis, guidebooks and articles written by theorists and practitioners of graphic design all of them allow us to look at the problem of visual identity, image, reputation and brands from other than psychological, place marketing or a managerial point of view. One of the examples of such approach is the model proposed by Beyrow and Vogt (Beyrow \& Vogt, 2015, p. 34), which has been taken into account when examining the logos of Polish cities.

\section{Theoretical assumptions}

The image (picture) is one of the very crucial issues in promotion (Kotler et al., 1993, p. 153; Kavaratzis, 2004, p. 67; Lynch, 1960; Anholt, 2009; Lopes, 2011). It is a cliché to say that we live in the era of the image domination over the verbal communication. The logic of spoken and written language involving the sequence of words is today replaced by the logic of image - the subject to the space logic in which at the same time - next to each other - different pictures may exist. When we speak or write words or sounds, they occur one after another. In the culture of image an interpretation of the sign is freer, although falls to indicate that the reading of the visual signs is often done through social and aesthetic conventions (Sturken \& Cartwright, 2001, p. 25). However, the watcher reads (interprets) the sign according to the individual perception of the mark, depending on its form, size, location in the wider space or the neighbouring symbols.

The culture of image affects every aspect of social and economic lives, including and perhaps above all, regional development (Ward, 1998; Urry $\&$ Larsen, 2011). For decades - the typical for the production of goods and services - activities are now successfully used in place marketing. Thus, building a city brand has become one of the key forms of place governance to encourage tourists, attract investors and integrate residents of the place. Emphasizing uniqueness, but also indicating the added value of the site, logo allows to get to know the features of the city and its 'products' (Caldwell \& Freire, 2004, pp. 50-61). To meet such a requirement, the logo should be visible, recognizable and enforceable to remember (Francesconi, 2014, p. 132). What is more, researchers, especially sociologists and anthropologists, have begun to appreciate the image and visual 
communication (Magala, 2012; Francesconi, 2014). Analysis of the logos, which are forms that combine the content (informing about the place and its symbols) and a form of space order (logos are trademarks practiced in the two-dimensional space documents, as well as three-dimensional space signs on the roads, buildings, etc.), is also increasingly common. Elizabeth Chaplin emphasizes that the recognition of the brand stimulates associations with the quality, respect, reliability and innovation. The image is used to establish the identity in the market (Chaplin, 1994, p. 143). The consequence of the image culture, also in place marketing, is to create and implement visual identity what means to practice different kinds of codes of expression, including the logo, typography and graphics (Olins, 2008; Dinnie, 2014, pp. 43-44; Hanna \& Rowley, 2011; Ashworth \& Kavaratzis, 2009, p. 524).

\section{Research method}

Therefore, the authors of this study have examined the pictures (logos) applying the content analysis technique, understood as research method serving the objective, systematic and quantitative description of the message content (Lisowska-Magdziarz, 2004, p. 13; Rose, 2001, p. 55). Content analysis of the graphic symbols used in promotion consists of four stages (Rose, 2001, pp. 56-66):

- finding images;

- devising categories for coding;

- coding the images;

- analysing the results.

To develop categories for coding the authors used a theoretical model of the brand - also territorial - proposed in the book: Marks of Excellence (Mollerup, 2013) providing three layers of the analysis: the brand core, brand presentation and brand image (Figure 1).

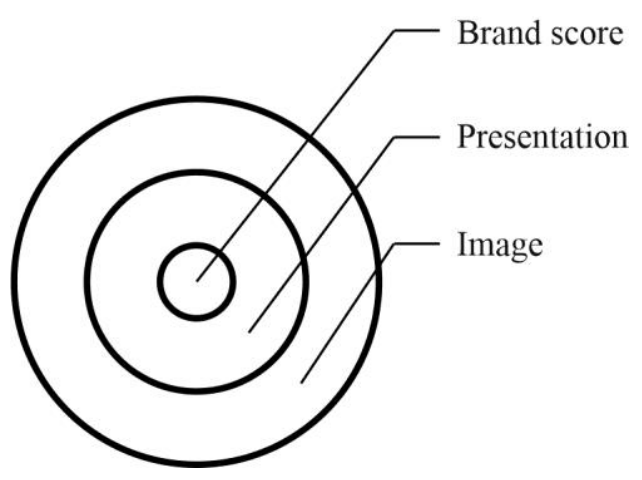

Figure 1. A theoretical model of the brand by Per Mollerup (source: adapted from: P. Mollerup, Marks of excellence, second edition (revised, expanded and updated), London 2013, p. 46)
The presented study focuses on the presentations what logo of a city or county communicates to stakeholders. The study was completed on 31 January 2020.

The following methods were used in empirical research:

- interviews with expert judges who were asked questions about the graphic professionalism of the researched logos;

- observation during study trips to collect data;

- interviews with employees of municipal offices to confirm the appropriateness and use of logos collected during the observation;

- logos' content analysis.

\subsection{Finding images}

The authors have inquired graphic symbols of the territorial units in Poland referring to administrative criteria. To make a study the following places have been selected:

- all cities with the special administrativemunicipality and county status, so-called "City-county" - at the time of the survey there were 66 such units;

- all capitals of rural districts understood as the seat of the local self-government ("Starostwo" in Polish) - at the time of the study there were 269 such units.

Altogether 335 local government units have been researched ${ }^{2}$.

The choice of such research population allows examining different sizes cities, located in diverse geographical regions i.e. lakes, mountains, seaside, etc., having various specializations and characterized by wide-ranging history that results from the different history architecture and urbanism. However, one may stress that this is not the study of cultural anthropology or history; nevertheless, so diverse population allows to make some general conclusions regarding visual identity and its application in marketing practice.

\footnotetext{
${ }^{2}$ It should be noted that the total number of rural districts (poviats) in Poland is 314 . However, in 45 cases the seat of the "Starostwo" (county office) is located in the neighboring city with the special administrative-municipality and county status. For example, the seat of the county office of the Poznan poviat comprising 17 municipalities around the city of Poznań is located in Poznań. Such poviats (rural districts) in Poland are described as "bagels" (cf. Ministerstwo Administracji i Cyfryzacji, 2013).
} 


\subsection{Categories for coding}

The authors have analysed the signatures using four different typologies. The first one resulted from the experience of observers and for the presented study is called an 'inspiration' (Hyland $\&$ Bateman, 2014). The second refers to the basic Mollerup's taxonomy (Mollerup, 2013). The third follows the basic Beyrow and Vogt's categorization and the last - considers a construction of a signature.

In the first typology, the authors divided the logos used in the promotion of cities into two broad categories: representational and abstract. Representational logos were further divided into cultural and natural. The final taxonomy is (see: Table 2):

- cultural inspiration, the inspiration could be existing now in the past architectural object, urban system, person or event. For cultural inspiration signs inspired by maps or coats of arms were included;

- nature inspiration, what means any kind of plants, animals, rivers, landscapes, etc.;

- abstraction, what means different visual forms such as arrows, triangles, dots, well-known symbols (e.g. power switch), characters, etc.

In the second taxonomy, tree of trademarks by Per Mollerup was adopted. The author divides graphic marks into two groups: picture marks and letter marks. Picture marks are divided into figurative and non-figurative marks. Figurative marks might be depictive, metaphoric or found. Non-figurative marks - they are symbols such as arrows, bubbles, etc. Letter marks can be just name marks or abbreviations.

Mollerup's taxonomy is detailed and organizes the symbols used by business organisations, NGOs, government agencies and local government. The developed division of signs is the result of long-lasted research and practical experience of the author. Application of this typology to encode symbols used in the presentations of the Polish cities and towns allows getting to know the design practice and trends in their visualization. Mollerup's model clarifies graphic motives used in logos (see Table 3).

The third type of categorization - the model proposed by Beyrow and Vogt - offers an analysis of the logo content. The model of German researchers has been divided into three basic groups of related contents of logos: Substanz (substance), Presence (presence) Referenz (reference) (Beyrow \& Vogt, 2015, p. 34).
Substance is what the city offers to stakeholders. It is a kind of substance demonstration of objects that really exist in a given city. Presence means to show the city as such. The example of such signatures is the proclamation of the existence of slogandominant signature. Logo itself 'talks' about the city. Reference means a stabilized symbol that is well known and clearly understood as well as interpreted, e.g. coat of arms or famous people (see Table 4).

The fourth classification used for the analysis of the logos is the formal typology of signatures. The initial query of logos as well as literature review allowed to extract the following types of logos: (a) graphic symbol - the logo, which is characterized by only graphic presentation; (b) graphic symbol with the logotype - a two-piece sign; (c) logo with the slogan; (d) logotype with the slogan; (e) logotype (this category included the signs of letterpress type intervention such as: strikethrough, underline, ligatures, unusual letter forms, accented characters, and others); (f) full signature - according to the Wheeler's characteristics it consists of a graphic symbol, a logo and a slogan (Wheeler, 2018, p. 54).

The results are presented in Figure 2.

\section{Alina Wheeler signature}

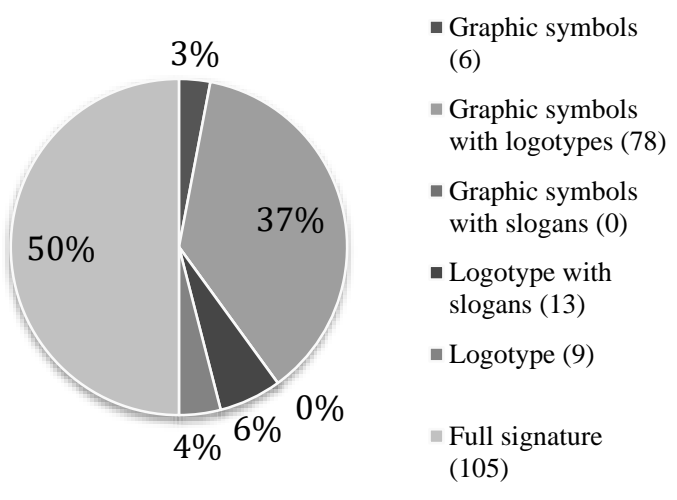

Figure 2. Signatures of cities and towns (source: authors' research)

\section{Results: Characteristics of the signatures of cities and towns in Poland}

Empirical research has been carried out in four stages (Lucarelli \& Berg, 2011, p. 11):

1. Identification of the cities that using logos in promotional practice. That phase of research was devoted to query of the official websites. In some cases, additional verification by direct contact (personally or by phone) was made. As a result, there have been found signatures of the Polish 
cities and towns. This stage is summarized in Table 1.

2. Categorization of found signs using the described above typologies.

3. Quantity analysis.

4. Multidimensional analysis of the identified signs $^{3}$.

Table 1. Numbers of identified signatures of the Polish cities and towns in March 2017 (source: authors' research)

\begin{tabular}{|c|c|c|c|c|c|}
\hline \multicolumn{2}{|c|}{ Towns } & \multicolumn{2}{c|}{ City-Counties } & \multicolumn{2}{c|}{ Total } \\
\hline $\begin{array}{c}\text { No. } \\
\text { of } \\
\text { units }\end{array}$ & $\begin{array}{c}\text { No. of } \\
\text { units } \\
\text { having } \\
\text { logos }\end{array}$ & $\begin{array}{c}\text { No. of } \\
\text { units }\end{array}$ & $\begin{array}{c}\text { No. of } \\
\text { units } \\
\text { having } \\
\text { logos }\end{array}$ & $\begin{array}{c}\text { No. } \\
\text { of } \\
\text { units }\end{array}$ & $\begin{array}{c}\text { No. of } \\
\text { units } \\
\text { having } \\
\text { logos }\end{array}$ \\
\hline 269 & 155 & 66 & 56 & 335 & 211 \\
\hline
\end{tabular}

Out of 335 cities and towns surveyed, 59.4\% units of local government decided to use in practice this form of communication, the other prefer to take advantage of coats of arms or do not use any symbols that allow to identify a given city. In the case of towns, logo is used by $52.3 \%$ of them, and cities almost all of them $-84.4 \%$. Ten of the cities do not use logos: Włocławek (the logo ceased to be used around 2017), Nowy Sacz (The city officially, by ordinance of the city president, gave up the use of the logo in December 2018), Tarnów (the logo ceased to be used around 2017) Świętochłowice, Kielce, Torun - these cities used to have a logo, but the signs was withdrawn around 2018, Tarnobrzeg - logo developed, but has not been implemented, Krosno - the city that has not worked on the development of promotional character of the city so far, Przemyśl logo is used only for tourism promotion (visitprzemysl.pl) and Piekary Śląskie, where in 2010 authorities decided not to implement a city visual identification and so far there has not made any decision in this field.

In several cases, the decisions require further clarification. This applies in particular to the following cities:

- Szczecin applies two different signs. The first one is used by the City Hall and the second used as a symbol of the city understood as a community. In the case of research, the logo that symbolised Szczecin as a community was considered.

- In one case the logo has not been included into these statistics. City Frankfurt

\footnotetext{
${ }^{3}$ The stage 4 is included in the book written by the authors of presented paper: Visual identity of the Polish regions, cities and counties (Adamus-Matuszyńska \& Dzik, 2017a).
}

(Oder) - Germany and town Słubice Poland, have one common visual sign that identifies both of them. However, one my find Polish and German versions ${ }^{4}$.

The authors checked whether Polish cities have - at least a simplified - City Visual Identification System (CVIS). By visual identification system (VIS), the authors understand the systematic collection of the following graphical elements: logo (signature, character), visual system (fonts, colours, images and other graphics elements) and text (verbal signs) used to formulate unique and coherent transmission (Adams \& Morioka, 2006, p. 18). This definition means that the only logo standardization is not yet a visual identification system. Studies have shown that among 213 researched cities and towns in 102 visual identifycation systems are applied.

\subsection{Typology: Inspirations}

Based on the observation, the authors decided to divide the collected signs into three categories which reveal the inspiration of the authors of the researched visual symbols. The first presenting cultural objects such as monuments, sacred buildings, remains, traditional symbols, images of wellknown persons, etc. The second group of characters consists of symbols related to nature, such as animals, plants, rivers, mountains, etc. The third category are abstract symbols.

Symbols related to "culture" are dominant in the Polish visual practice of the local government units. Buildings genuinely existing in the researched places such as castles, towers, churches, town halls, distinctive and well-known architectural objects (e.g. bridges) are shown in their visual representtation. "Nature" is also significantly manifested in the presentation of the identity and symbols of the place. Elements of nature refer to actually existing objects such as rivers, lakes, forests, wild animals and related forms of human activity (e.g. tourism). Abstract symbols are the least popular forms of presentations; although during the study authors noted that the number of these visual signs slowly grows.

Table 2. Inspiration typology (source: authors' research)

\begin{tabular}{|c|c|c|c|}
\hline Culture & Nature & Abstract & Total \\
\hline 115 & 43 & 53 & 211 \\
\hline $55 \%$ & $20 \%$ & $25 \%$ & $100 \%$ \\
\hline
\end{tabular}

\footnotetext{
${ }^{4}$ Cf. web pages: https://slubice.pl/frankfurt-nad-odra/ and: https://www.frankfurt-oder.de/ [accessed 01.04.2020]
} 
The analysis of logos of Polish cities and towns lets us draw the following conclusions:

1. In marketing practice of the Polish cities and towns apart from signatures unambiguously referring to these three categories one may find complex logos that indicate more than one feature of the place (e.g. Człuchów, Łowicz), therefore the authors needed to make arbitrary decisions and followed a dominate theme in the presentation.

2. It is difficult to indicate a major object (symbol) of cultural inspiration in these presentations. The authors have identified various signs that agreed to have cultural meaning, such as 'skyline', the city hall, a castle or a palace, a monument, and even a literally depicted water pump.

3. Visual signs of the Polish cities and towns indicating cultural inspiration are intensely involved in history. There is only one logo among identified which illustrates an object built after 1945 - it is a bridge in Zgorzelec.

4. In case of inspiration called 'nature' the situation seems complex because many logos combine motives of plants, landscape or/and animals as well as human activities connected with the nature such as riding a bicycle or sailing in the same figure.

5. Abstract logos are very diverse either in many different forms or various content. There are signs using letters in numerous ways, some signs refer to the coat of arms or slogans. In this group of logos, one may find signs revealing links with modernity of a given place.

An important trend resulting from the analysis of inspiration that was identified during the study, is broadly understood "the past". Poland presents itself in the promotional symbols as an idyllic country in which nature, tradition and history are the most important values. It is interesting that only few logos refer directly to industrial facilities, e.g. Starachowice, Dzierżoniów, Żyrardów. However, these three towns used to be very industrial, today manufacturing is much less important. The authorities of these towns refer to the industrial heritage.

\subsection{Typology: Per Mollerup taxonomy}

The second typology used to examine promotional signs - the Mollerup taxonomy - has been chosen due to its graphical meanings. It is detailed and organizes the symbols used in logos (Mollerup,
2013, pp. 100-125). By the term "figurative marks" the author understands three groups of characters that arise depending on the relationship between what they show and what they represent. That is, their meaning depends on the relationship between the trademark and its object, i.e. the company, product or place it symbolises. Figurative signs are descriptions, show recognizable things, paintings, portraits. The first figurative sign is a descriptive sign, which is a specific image that explicitly refers to the object. It shows figures, i.e. existing buildings, plants, animals, technical equipment, etc. For example, fish is a symbol of a restaurant serving fish dishes. The relationship between the sign and the object is therefore justified. There are three types of them: metaphoric, descriptive and found marks.

Non-figurative characters include various types of arrows, lines, stars, typographic symbols etc., that do not relate to any specific thing in the observed reality. Non-figurative signs only apply directly to their objects (company, product, place, events). These are symbols in which the relationship between the trademark and its object is arbitrary. The symbols used do not have the form of figures, they are signs that only after some time are associated with a specific object, although in the process of their creation they receive specific explanations. As a rule, these signs are accompanied by explanations and management recommenddations on what they are meant. The last group of analysed signs referring to the Mollerup's taxonomy there are letter marks which are divided into name marks and abbreviations.

The use of this typology to code the signs and symbols used in the presentations of Polish cities allows to learn about design practice and trends in how to visualize the specificity and identity of a city or region. Taking advantage of this logo typology allows for in-depth analysis of the visual symbols' content. It shows that the Polish cities and towns use mainly figurative marks - descriptive and metaphorical. The dominance of such logos confirms the conclusion coming from the inspiration analysis mentioned above.

Table 3. Signatures of cities and towns in Poland according to the taxonomy of Per Mollerup (source: authors' research)

\begin{tabular}{|c|c|c|c|}
\hline $\begin{array}{c}\text { Figurative } \\
\text { marks }\end{array}$ & $\begin{array}{c}\text { Non-figurative } \\
\text { marks }\end{array}$ & $\begin{array}{c}\text { Letter } \\
\text { marks }\end{array}$ & Total \\
\hline 160 & 22 & 29 & 211 \\
\hline $76 \%$ & $10 \%$ & $14 \%$ & $100 \%$ \\
\hline
\end{tabular}


The dominance of figurative marks (often generalized descriptive signs showing the Platonic essence of things, e.g. river, the sun) indicates a large attachment of self-governments as purchasers and logos' designers to symbols literally associated with the identity of promoted places. Signatures often refer to objects that actually exist, and a particular local government offers them to its stakeholders (tourists, investors, citizens). German researchers (Beyrow \& Vogt, 2014, p. 34) call such signs as substance (Ger. Substanz). Brand core presented in the visual demonstration of the place - what is manifested especially in their descriptions and justifications written in formal documents - should disclose clearly features typical for a particular place. In most signatures, there is no message to encourage a visitor to deepen the knowledge about city or town. Signs such as sailboats or rivers rather incline why one should visit or stay in the certain place, nor gain knowledge about location.

\subsection{Typology: Beyrow-Vogt's typology}

German researchers: Matthias Beyrow and Constanze Vogt, the authors of the first study analysing promotional signs of cities in Germany, propose the division of signatures into three categories:

- signs showing what the city has to offer, demonstrating a substance (German: Substanz);

- signs indicating existence, drawing attention to presence (German: Präsenz);

- signs that draw attention to the value of accepted symbols, i.e. reference (German Referenz).

In assigning the logo to the appropriate category, the authors are guided by the methodlogy that Gillian Rose calls the "compositional interpretation" (Rose, 2001, p. 33 and following). They make decisions based on two guidelines. The first is to read the motif understood as the main graphic theme. The second guideline concerns form, i.e. colour, structure, shape, spatial organization, etc. The only criterion for decision is visual dominance of a motif in the particular logo.

Table 4. Signatures of cities and towns in Beyrow Vogt's typology (source: authors' research)

\begin{tabular}{|c|c|c|c|}
\hline Substance & Reference & Presence & Total \\
\hline 150 & 25 & 36 & 211 \\
\hline $71 \%$ & $12 \%$ & $17 \%$ & $100 \%$ \\
\hline
\end{tabular}

The application of the classification proposed in the book "Städte und Ihre Zeichen" reveals that signs which present genuinely existing resources (Substanz) dominate. Cities prefer to employ well known, recognizable and relatively widely accepted objects, things or phenomena in their visual identification. Logos reveal something that exists, rather than suggest, promise or initiate activity from a logo recipient. They implement the descriptive function of identification, rather than differentiation; they emphasis the connotation rather than the denotation.

Such conclusion is also confirmed when reading the explanations of the logo available on the websites of cities and towns or in the visual identification systems descriptions. They are long, ambiguous and mainly refer to the physical resources accessible in the specific place. They show that the logo significance is to highlight what a place has. These are the most common natural and cultural resources, centuries-old tradition and history. This makes these messages, which are transmitted by the logos of the Polish cities and towns, overloaded. It causes certain consequences of discrepancies between the outer presentation of a place in the logo, and its brand core.

\subsection{Typology: Alina Wheeler's signature model}

The fourth typology of the Polish cities and towns used in the examination refers to the Alina Wheeler's signature model. The authors have distinguished six different types of visual representtations considering Wheeler's definition of signature (Wheeler, 2018, p. 54).

The dominant logos are full signatures containing all three elements taken into account by Alina Wheeler. This proves that the creators of logos or local governments want to include in these signs as much content as possible. As the result, logos do not only illustrate cities, but also contain a message, keynote idea or leitmotif. Therefore, at this point of the analysis, it is important to emphasize the significant number of signs containing slogans (taglines). These are close in their formula to the heraldic motto. Their goal is to identify the location and reveal the message of a particular place (like corporate mission statement). The graphic symbol (brandmark) shows the existing resources of the place and slogan dictates interpretation of the promotion sign.

The promotional signatures used are very diverse. The analysis shows that cultural elements dominate, signs illustrating really existing objects, most often architectural ones, and associations with nature are less noticeable. Poland, perceived 
by cities logos, does not identify itself as a modern country, but rather as a traditional one. This fact confirms the considerable attachment of Polish residents to history, the past, known objects, and thus objects with which human memory is associated. This thesis is confirmed by the quantitative analysis of visual signs. Admittedly, many descripttions of logos and promotional slogans state that the place is open, hospitable, creates opportunities, is active and lies in the right place. These general incentives can be interpreted in many ways, also as support for the tourist offer.

\section{Conclusions and discussion}

The authors believe that the hypothesis has been confirmed - the logo can serve as a preliminary (directional) indicator that the local government (administration) develops a marketing orientation. However, the content analysis carried out above indicates a whole range of additional problems and issues of discussion.

Without going into the subject matter of graphical excellence (quality of presentation) of the signatures promoting cities and towns in Poland, one may stress that the visual identity is very traditional. In a formal sense (construction) all studied logos are static and constant. They meet or attempt to meet the "classical" (Stones, 2009, p. 4) requirements of a good logo. The intention is to present a clear, simple, recognizable, distinct, reproducible and readable sign. There are some attempts to make signatures more flexible, especially by the local government units which use systems of visual identification. CVISs are sometimes enriched with additional components (thematic pictograms, graphic symbols, illustration guidelines, etc.). This does not change the fundamental assessment that the visual identification of Polish cities and towns is static.

The authors have not found any signature that would be fluid and dynamic, based on the mechanism of logo generating or built as a flexible system of identification such as VIS of Porto or Bologna. Attempts to give flexibility to a visual identification come down to developing different versions of the signature for specific applications (e.g. the logo has two or three options: business, tourist and culture as it happens in case of Będzin or Jaworzno) or expansion of basic elements (richer colours, additionnal decorative elements) as it is suggested in the case of Grudziądz.

The logos of cities and towns neither have connection to the visual identification of Poland as a state nor refer to the regional (provincial) visual identification. Each unit of the local government employs its own criteria and principles. In many specialized forums and blogs in the Internet, and also in the graphic design magazines, one may find such terms used as "logosis", "logomania", when describing logos of the Polish towns.

In summary, a city in Poland promotes itself mainly by substantial elements (Ger. Substanz), and is less linked to the presentation of the abstract symbolism. The signatures are imitative; they are rarely projected into the future. The most typical symbols are connected with history and nature. It turns out that the heritage is an integrated component of the character of a brand of cities and towns (Urde et al., 2007, p. 5). Other trends are difficult to clearly define and describe, although it seems that the thesis regarding the construction of promotional messages on resources and not on products has also been confirmed.

The city promotion uses a logo only as the visual symbol and in such a way meets hardly one of its functions - information. It is difficult to point out signs that have impact on recipients' thoughts and opinions, logo stimulating or encouraging to "buy" the place itself and its products. This of course requires further research, although there are studies showing that high-quality logos can significantly influence purchasing decisions, also in the case of places (territories) (Lee et al., 2012). They are seen as advertising tools, not as a means of building a bond between the community and the administration or reducing tension between globalism and localism (Malpas, 2009, p. 192). It seems that in many cases the logos themselves are to replace the communication strategy and marketing activities, and they - without additional professional support - should encourage stakeholders to take advantage of the offer of the local government units.

The last finding of the analysis is the fact that the cities and towns do not have one (definite) promotional logo. For example, projects co-financed by the European funds, events, subordinate institutions (e.g. public transport) use their own logos without any references to the logo of the place, where they operate. Considering the fact that the self-government has to - at the same time support the residents (administration), convince tourists (place as a destination) and attract investors or prospective residents (location of activity), such diverse visual identification is a non-functional solution. The large number of logos used in practice brings two negative consequences. Firstly, it complicates to identify the sender (the place). Secondly, it hinders the effectiveness of the 
funds spent for brand building and management of these brands (Beyrow \& Vogt, 2014, p. 10).

The use in the quantitative analysis of analytical categories developed on the ground of graphic design theory has shown that its use is thought-provoking and gives significant results in the study of territorial brands. In particular, it is worth to pay attention to:

- Large number of full signatures in researched populations (105 of 211) which allows to make further examination, for example relationships between picture and text in a promotional sign as well as the text itself according to fonts, colours, included slogan etc. What is more, one may notice that analysis of logo perception without other elements such as fonts, slogans, colours and composition may lead to erroneous conclusions. What means, that if a sender (city or region) treats a signature as a whole, a researcher needs to examine a sign in the same way.

- In the place marketing literature one may find the conclusion stressing that there are many signs overestimating nature in place marketing especially concerning tourism (Kozak, 2009; Pike, 2008). The presented analysis does not confirm such a supposition (43 such signs of 192). However, this may result of examined population towns and cities. Others such as rural destinations may modify that statement (cf. Adamus-Matuszyńska \& Dzik, 2017c).

- Both used in the research typologies - Per Mollerup and Beyrow-Vogt - let us emphasise that the ideas in terms of resources of a place dominate in the selfgovernment units' presentations. Logo is supposed to be a narration about the place not a synthetic, graphical shortcut revealing the core values of a brand. The practical consequences of such thinking about visual symbols may be unfavourable, i.e. logos begin to require explanations of the description contained in them that is obvious for senders (in the researched cases - the public institution which represents the particular community) but might be unreadable for receivers.

Therefore, it is worth to stress that the categories developed by graphic designers such as Gibbs, Molleup, Wheeler, Beyrow, Vogt, gave interesting cognitively results and, as a consequence, may have an impact on further theoretical considerations concerning the process of visual identity of a place or an organisation. Taking into account the presented deliberations, one may find evidence for an interdisciplinary approach postulated by Hankinson or Kavaratzis (Hankinson, 2010; Kavaratzis \& Hatch, 2013). If so, then theories of place marketing need to fill the existing gap in visual identity models by the references to the theory of graphic design. One of the reasons for current lack of such deliberation might be the graphic form of works on the theory and history of graphic design, with rather reduced written explanation of these theories.

The obtainable results of the research encourage formulating further research directions related to the promotion of cities. First, a noteworthy direction seems to be a qualitative and quantitative analysis of promotional slogans, because more than half of researched logos (118 of 211) contain the slogan. Semantic analysis of slogans can reveal unintended outcomes by the creators, both positive and negative. The second field of the analysis, which might be pointed out, is to identify other symbols than visual. During the study it was found that many local governments have adopted their own bugle calls, signals and anthems. It seems that this research field would be interesting for e.g. musicologists interested in marketing, especially territorial marketing.

An important direction of research is the analysis of visual identification systems, because such systems contain information and interpretation of the content of the promotional logos. The VIS has two functions: identification and distinguishing. Formal analysis, e.g. colours used in promotional signs, allows revealing similarities among different cities, and therefore may indicate the lack of distinguishing function.

An extremely essential and stimulating field of deepened research would be to examine the logo reception in different target groups (visitors, investors, inhabitants). These are issues suggested for further sociological and marketing research.

The authors believe that they indicated the usefulness of models developed by graphic designers in the analysis of territorial brands. Graphic designers based on both practical experience and the specificity of the creative process propose typologies of visual signs that allow their use in indepth analysis of the content of promotional symbols. They allow to analyze the logo practiced in territorial marketing and place branding from a different perspective than the promotional one, while the literature on the subject does not basically refer to the theory of graphic design. 
Therefore, one of the additional, debatable conclusions of completed research on the content of city $\log o$ is the assumption about the need for cooperation of territorial marketing specialists with graphic designers, taking into account the theory of graphic design in analytical, research, but also implementation works related to building the visual identity of cities and regions. The several examples of interdisciplinary projects combining approaches developed in the field of social sciences and graphic design have given very noteworthy results justifying the above thesis (Baur \& Thiery, 2013; Beyrow \& Vogt, 2015; Adamus-Matuszyńska \& Dzik, 2017a).

\section{References}

Adamus-Matuszyńska, A., \& Dzik, P. (2017a). Tożsamość wizualna polskich województw, miast $i$ powiatów. Identyfikacja, prezentacja, znaczenie. Adam Marszałek \& ASP w Katowicach.

Adamus-Matuszyńska, A., \& Dzik, P. (2017b). Measurement of local government unit marketing orientation. Studia Ekonomiczne. Zeszyty Naukowe Uniwersytetu Ekonomicznego w Katowicach, 336, 172-182.

Adamus-Matuszyńska, A., \& Dzik, P. (2017c). Logo w komunikacji marketingowej jednostki samorządu terytorialnego. Marketing i Rynek, 26-42.

Adams, S., \& Morioka, N. (2006). Logo design workbook: A hands-on guide to creating logos. Rockport Publishers.

Anholt, S. (2009). Introduction. In Handbook on tourism destination branding. WTO\&ETC.

Anttiroiko, A.-V. (2014). The political economy of city branding. Routledge. https://doi.org/10.4324/9780203782187

Ashworth, G., \& Kavaratzis, M. (2009). Beyond the logo: Brand Management for the cities. Journal of Brand Management, 6(8), 520-532. https://doi.org/10.1057/palgrave.bm.2550133

Barry, P. (2016). The advertising concept book. Thames \& Hudson.

Baur, R., \& Thiery, S. (2013). Don't brand my public space. Lars Mueller.

Beyrow, M., \& Vogt, C. (2015). Städte und ihre zeichen. Identität, strategie, logo. avEdition.

Bekkers, V., \& Moody, R. (2015). Visual culture and public policy. Towards a visual polity. Routledge. https://doi.org/10.4324/9781315776132

Caldwell, N., \& Freire, J. R. (2004). The differences between branding a country, a region and a city: Applying the brand box model. Brand Management, 12(1), 50-61. https://doi.org/10.1057/palgrave.bm.2540201

Chaplin, E. (1994). Sociology and visual representation. Routledge.
Dinnie, K. (2014). Nation branding: concepts, issues, practice. Butterworth-Heinemann. https://doi.org/10.4324/9781315773612

Francesconi, S. (2014). Reading tourism texts. A multimodal analysis. Channel View Publications. https://doi.org/10.21832/9781845414283

Fuery, P., \& Fuery, K. (2003) Visual cultures and critical theory. Oxford University Press Inc.

Gibbs, D. (2014). See how you feel. In A. Hyland, \& S. Bateman (Eds.), Symbol. Laurence King.

Glińska, E. (2016). Budowanie marki miasta. Koncepcje, warunki, modele. Wolters Kluwer.

Hankinson, G. (2010). Place branding research: A crossdisciplinary agenda and the view of the practitioners. Place Branding and Public Diplomacy, 6(4), 300-315. https://doi.org/10.1057/pb.2010.29

Hanna, S., \& Rowley, J. (2011). Towards a strategic place-brand management model. Journal of Marketing Management, 27(5-6), 458-473. https://doi.org/10.1080/02672571003683797

Hyland, A., \& Bateman, S. (Eds.). (2014). Symbol. Laurence King.

Kavaratzis, M. (2004). From city marketing to city branding. Place Branding, 1(1), 58-73. https://doi.org/10.1057/palgrave.pb.5990005

Kavaratzis, M. (2009). Cities and their brands: Lessons from corporate branding. Place Branding and Public Diplomacy, 5(1), 26-37. https://doi.org/10.1057/pb.2008.3

Kavaratzis, M., \& Hatch, M. J. (2013). The dynamics of place brands: An identity-based approach to place branding theory. Marketing Theory, 13(1), 69-86. https://doi.org/10.1177/1470593112467268

Kotler, P., Haider, D. H., \& Rein, I. (1993). Marketing places. Attracting investment, industry, and tourism to cities, states, and nations. The Free Press.

Kozak, M. W. (2009). Turystyka i polityka turystyczna a rozwój: między starym a nowym paradygmatem. Scholar.

Lee, S., Rodriguez, L., \& Sar, S. (2012). The influence of logo design on country image and willingness to visit: A study of country logos for tourism. Public Relations Review, 38, 584-591. https://doi.org/10.1016/j.pubrev.2012.06.006

Lisowska-Magdziarz, M. (2004). Analiza zawartości mediów. Przewodnik dla studentów. NiF.

Lopes, S. D. F. (2011). Destinations image: origins, developments and implications. Pasos, 9(2), 305315. https://doi.org/10.25145/j.pasos.2011.09.027

Lucarelli, A., \& Berg, P. O. (2011). City Branding: A state-of-the-art review of the research domain. Journal of Place Management and Development, 4(1), 9-27.

https://doi.org/10.1108/17538331111117133 
Lynch, K. (1960). The image of the city. MiT Press.

Magala, S. (2012). Antropologia wizualna. In D. Jemielniak (Ed.), Badania jakościowe. Podejścia $i$ teorie (Vol. 1, pp. 141-166). Wyd. Naukowe PWN.

Malpas, J. (2009). Cosmopolitanism, branding and the public realm. In S. H. Donald, E. Kofman, \& C. Kevin (Eds.), Branding cities. Cosmopolitanism, parochialism and Social Change. Routledge.

Ministerstwo Administracji i Cyfryzacji. (2013). Polskie obwarzanki.

http://www.lzg24.pl/sites/default/files/ministerstwo.pdf

Mollerup, P. (2013). Marks of excellence. The history and taxonomy of trademarks (2 ed.). Phaidon.

Olins, W. (2008). Brand handbook. Thames and Hudson.

Pike, S. (2008). Destination marketing: an integrated marketing communication approach. Elsevier.

Rivas, M. (2012). CityLogo. Innovative place brand management. URBACT.

Rose, G. (2001). Visual methodologies. An introduction to the interpretation of visual materials. Sage Publication.

Soenen, G., \& Moingeon, B. (2002). The five facets of collective identities. In G. Soenen, \& B. Moingeon (Eds.), Corporate and organizational identities. Integrating strategy, marketing, communication and organizational perspectives. Routledge.
Stones, J. (2009). No rules logos. Radical design solutions that break the rules. RotoVision.

Sturken, M., \& Cartwright, L. (2001). Practices of looking. An introduction to visual culture. University Press.

Urry, J., \& Larsen, J. (2011). The tourist gaze 3.0. Sage.

Urde, M., Greyser, S. A., \& Balmer, J. M. T. (2007). Corporate brands with the heritage. Brand Management, 15(1), 4-19. https://doi.org/10.1057/palgrave.bm.2550106

van den Bosch, A. L. M., de Jong, M. D. T., \& Elving, W. J. L. (2004). Managing corporate visual identity: use and effects of organizational measures to support a consistent self-presentation. Public Relations Review, 30, 225-234. https://doi.org/10.1016/j.pubrev.2003.12.002

Vuignier, R. (2017). Place branding \& place marketing 1976-2016: A multidisciplinary literature review. International Review on Public and Nonprofit Marketing, 14(4), 447-473. https://doi.org/10.1007/s12208-017-0181-3

Ward, S. (1998). Selling places: the marketing and promotion of town and cities, 1850-2000. Taylor and Francis.

Wheeler, A. (2018). Designing brand identity. John Wiley \& Sons. 